ФИЗИRO-MATEMATИYECRИE HAУRИ

UOT 519.852 .6

\title{
THE DETERMINATION OF AN UPPER BOUND OF THE MAXIMUM VALUE OF THE OBJECTIVE FUNCTION IN AN INTERVAL MIXED- BOOLEAN KNAPSACK PROBLEM
}

DOI: $10.31618 /$ ESU.2413-9335.2019.2.66.305

Nigar Oktay Mammadli

Science researcher,

Institute of Control Systems of ANAS

\begin{abstract}
This work considers the finding of an upper bound of maximum values of an objective function for an interval mixed-Boolean knapsack problem. For this purpose, some majorizing function with one variable is constructed. It is shown, that this function is piecewise linear, continuous, non-differentiable, and convex. Therefore, it has a unique minimum. Thus, to minimize this function, a descent algorithm has been developed. It is proved that the minimum values of an objective function of the interval mixed-Boolean problem coincide with maximum values of continuous problem .
\end{abstract}

\section{АННОТАЦИЯ}

В работе рассматривается нахождение верхней границы максимального значения целевой функции для интервальной частично-Булевой задачи о ранце. С этой целью построена некоторая мажорирующая функция с одной переменной. Показано, что эта функция кусочно-линейная, непрерывная, недифференцируемая и выпуклая. Следовательно, имеет единственный минимум. Поэтому разработан алгоритм спуска для минимизации этой функции. Доказано, что минимальные значения целевой функции интервальной частично-Булевой задачи о ранце совпадают с максимальными значениями непрерывной задачи.

Keywords: an interval mixed-Boolean knapsack problem, an upper bound, a majorizing function, a minimization algorithm.

Ключевые слова: интервальная частично-Булевая задача о ранце, верхняя граница, мажорирующая функция, алгоритм минимизации.

Introduction. The following interval mixedBoolean knapsack problem is considered:

$$
\begin{gathered}
\sum_{j=1}^{n}\left[\underline{c}_{j}, \bar{c}_{j}\right] x_{j}+\sum_{j=n+1}^{N}\left[\underline{c}_{j}, \bar{c}_{j}\right] x_{j} \rightarrow \max \\
\sum_{j=1}^{n}\left[\underline{a}_{j}, \bar{a}_{j}\right] x_{j}+\sum_{j=n+1}^{N}\left[\underline{a}_{j}, \bar{a}_{j}\right] x_{j} \leq[\underline{b}, \bar{b}], \\
0 \leq x_{j} \leq 1,(j=\overline{1, N}), \\
x_{j}=0 \vee 1,(j=\overline{1, n}),(n \leq N) .
\end{gathered}
$$

Here $0<\underline{c}_{j} \leq \bar{c}_{j}, 0 \leq \underline{a}_{j} \leq \bar{a}_{j},(j=\overline{1, N}), 0<\underline{b} \leq \bar{b}$ are given integers.

In other words, these problems are particular cases of (1)-(4).

Note that problem (1) - (4) is more general than the problems such as knapsack problem, the interval knapsack problem, the linear programming problem with one constraint, and the interval linear programming problem with one constraint.

It should be noted that in [1-10] Boolean programming problems with exact or inexact data were investigated. In these papers, the problems of mixedBoolean programming, with the exception of $[4,6]$ were not considered. In the above works algorithms of approximate solutions, based on various concepts were developed. And to assess the deviation of approximate solutions from the optimal, the considered problem is solved without the condition of integer variables, i.e. as a linear programming problem. As a result, we obtain the upper bound of the optimal value and thereby evaluate the proximity of the approximate solution to the optimal one. Obviously, since these problems are included in the class of NP - complete, i.e. intractable, such an approach for assessing deviations can lead to certain difficulties associated with computer time, finding the coordinates of solutions that should not be found to assess proximity, or an amount of information. In this paper we consider the problem of finding the upper bound of the maximum value of the objective function for the interval mixed-Boolean knapsack problem. For this purpose, some majorizing function is constructed and an algorithm for minimizing this function has been developed.

Problem statement.

First of all, we note that problem (1) - (4) is included in the class of NP-

complete. Therefore, in order to find an optimal solution to a high-dimensional problem is almost impossible. Therefore, some algorithms have been 
developed for the approximate solution of such or more general problems [4, 6, 13].

Suppose that approximate solutions of the problem (1) - (4) were found by some method and the lower bound $f$ of the optimal value $f_{*}$ was determined. Since determining the value of $f_{*}$ is practically impossible, then to investigate the proximity of $f$ to $f_{*}$, it is necessary to know the upper bound of the optimal value $f_{*}$.

Note that to determine the upper bound $\bar{f}$, one can solve the interval linear programming problem, i.e. not taking into account condition (4), (see [9.10]). However, this approach of determining the upper bound $\bar{f}$ would be inappropriate, as it is necessary to determine the solutions $X=\left(x_{1}, x_{2}, \ldots, x_{N}\right)$ and the value $\bar{f}$ of the function (1) for this solution. Obviously, to assess the proximity of $f$ and $\bar{f}$, we do not need the solution $X=\left(x_{1}, x_{2}, \ldots, x_{N}\right)$ which to find is the main problem of [10-12]. Therefore, in this paper, the purpose is to develop a high-speed algorithm for finding only the upper bound $\bar{f}$.

\section{Theoretical justification of the method.}

Let $f_{*}$ is a value of the function (1) for an arbitrary admissible solution $X=\left(x_{1}, x_{2}, \ldots, x_{N}\right)$ including optimal solution, i.e.

$$
\sum_{j=1}^{n}\left[\underline{c}_{j}, \bar{c}_{j}\right] x_{j}+\sum_{j=n+1}^{N}\left[\underline{c}_{j}, \bar{c}_{j}\right] x_{j}=f_{*}
$$

We multiply both sides of relation (5) by (-1) and constraints (2) by some parameter $\lambda \geq 0$, respectively, and add it in parts:

$$
\left(\sum_{j=1}^{n}\left[\underline{a}_{j}, \bar{a}_{j}\right] x_{j}+\sum_{j=n+1}^{N}\left[\underline{a}_{j}, \bar{a}_{j}\right] x_{j}\right) \cdot \lambda-\sum_{j=1}^{n}\left[\underline{c}_{j}, \bar{c}_{j}\right] x_{j}-\sum_{j=n+1}^{N}\left[\underline{c}_{j}, \bar{c}_{j}\right] x_{j} \leq[\underline{b}, \bar{b}] \cdot \lambda-f_{*} .
$$

From here we obtain

$$
f_{*} \leq \sum_{j=1}^{n}\left[\underline{c}_{j}, \bar{c}_{j}\right] x_{j}+\sum_{j=n+1}^{N}\left[\underline{c}_{j}, \bar{c}_{j}\right] x_{j}-\left(\sum_{j=1}^{n}\left[\underline{a}_{j}, \bar{a}_{j}\right] x_{j}+\sum_{j=n+1}^{N}\left[\underline{a}_{j}, \bar{a}_{j}\right] x_{j}\right) \cdot \lambda+[\underline{b}, \bar{b}] \cdot \lambda .
$$

After some transformations we get:

Thus,

$$
\begin{gathered}
f_{*} \leq[\underline{b}, \bar{b}] \cdot \lambda+\sum_{j=1}^{n}\left[\underline{c}_{j}, \bar{c}_{j}\right] x_{j}-\lambda \cdot \sum_{j=1}^{n}\left[\underline{a}_{j}, \bar{a}_{j}\right] x_{j}+\sum_{j=n+1}^{N}\left[\underline{c}_{j}, \bar{c}_{j}\right] x_{j}-\lambda \cdot \sum_{j=n+1}^{N}\left[\underline{a}_{j}, \bar{a}_{j}\right] x_{j}= \\
=[\underline{b}, \bar{b}] \cdot \lambda+\sum_{j=1}^{n}\left(\left[\underline{c}_{j}, \bar{c}_{j}\right]-\lambda \cdot\left[\underline{a}_{j}, \bar{a}_{j}\right]\right) x_{j}+\sum_{j=n+1}^{N}\left(\left[\underline{c}_{j}, \bar{c}_{j}\right]-\lambda \cdot\left[\underline{a}_{j}, \bar{a}_{j}\right]\right) x_{j} .
\end{gathered}
$$

$$
f_{*} \leq[\underline{b}, \bar{b}] \cdot \lambda+\sum_{j=1}^{n}\left(\left[\underline{c}_{j}, \bar{c}_{j}\right]-\lambda \cdot\left[\underline{a}_{j}, \bar{a}_{j}\right]\right) x_{j}+\sum_{j=n+1}^{N}\left(\left[\underline{c}_{j}, \bar{c}_{j}\right]-\lambda \cdot\left[\underline{a}_{j}, \bar{a}_{j}\right]\right) x_{j}
$$

Obviously, for fixed $\lambda \geq 0$, the right-hand sides of (6) are a linear function. Assuming $x_{j}=1$ for positive coefficients, and $x_{j}=0$ for negative coefficients, we obtain the maximum value of the right-hand side of relation (6).

Then

$$
f_{*} \leq[\underline{b}, \bar{b}] \cdot \lambda+\sum_{j \in \omega_{1}}\left(\left[\underline{c}_{j}, \bar{c}_{j}\right]-\lambda \cdot\left[\underline{a}_{j}, \bar{a}_{j}\right]\right)+\sum_{j \in \omega_{2}}\left(\left[\underline{c}_{j}, \bar{c}_{j}\right]-\lambda \cdot\left[\underline{a}_{j}, \bar{a}_{j}\right]\right)
$$

or

$$
f_{*} \leq \sum_{j \in \omega_{1}}\left[\underline{c}_{j}, \bar{c}_{j}\right]+\sum_{j \in \omega_{2}}\left[\underline{c}_{j}, \bar{c}_{j}\right]+\left([\underline{b}, \bar{b}]-\sum_{j \in \omega_{1}}\left[\underline{a}_{j}, \bar{a}_{j}\right]-\sum_{j \in \omega_{2}}\left[\underline{a}_{j}, \bar{a}_{j}\right]\right) \cdot \lambda=L(\lambda)
$$

Here sets $\omega_{1}$ and $\omega_{2}$ are defined by the following formulas:

$$
\begin{gathered}
\omega_{1}=\left\{1 \leq j \leq n \mid\left[\underline{c}_{j}, \bar{c}_{j}\right]-\left[\underline{a}_{j}, \bar{a}_{j}\right] \cdot \lambda>0\right\}, \\
\omega_{2}=\left\{n+1 \leq j \leq N \mid\left[\underline{c}_{j}, \bar{c}_{j}\right]-\left[\underline{a}_{j}, \bar{a}_{j}\right] \cdot \lambda>0\right\} .
\end{gathered}
$$


Since this relation is true for any $\lambda \geq 0$, then this will also be true for the minimizing parameter $\lambda \geq 0$.

Thus,

$$
f_{*} \leq \min _{\lambda \geq 0} L(\lambda)
$$

This shows that to minimize the function $L(\lambda)$, it is necessary to consider this function in two versions, which corresponds to the optimistic and pessimistic problem [see 4]. Then,

where

$$
f_{*}^{o p} \leq \min _{\lambda \geq 0}^{o p}(\lambda),
$$

Here $b \in[\underline{b}, \bar{b}]$ is fixed and

$$
L^{o p}(\lambda)=\sum_{j \in \omega_{1}^{o p}} \bar{c}_{j}+\sum_{j \in \omega_{2}^{o p}} \bar{c}_{j}+\left(b-\sum_{j \in \omega_{1}^{o p}} \underline{a}_{j}-\sum_{j \in \omega_{2}^{o p}} \underline{a}_{j}\right) \cdot \lambda .
$$

$$
\begin{gathered}
\omega_{1}^{o p}=\left\{1 \leq j \leq n \mid \bar{c}_{j}-\underline{a}_{j} \lambda>0\right\}, \\
\omega_{2}^{o p}=\left\{n+1 \leq j \leq N \mid \bar{c}_{j}-\underline{a}_{j} \lambda>0\right\} .
\end{gathered}
$$

where

$$
f_{*}^{p e s} \leq \operatorname{minL}_{\lambda \geq 0} L^{\text {pes }}(\lambda)
$$

$$
L^{p e s}(\lambda)=\sum_{j \in \omega_{1}^{p e s}} \underline{c}_{j}+\sum_{j \in \omega_{2}^{p e s}} \underline{c}_{j}+\left(b-\sum_{j \in \omega_{1}^{p e s}} \bar{a}_{j}-\sum_{j \in \omega_{2}^{p e s}} \bar{a}_{j}\right) \cdot \lambda .
$$

Here $b \in[\underline{b}, \bar{b}]$ is fixed as well, and

$$
\begin{gathered}
\omega_{1}^{p e s}=\left\{1 \leq j \leq n \mid \underline{c}_{j}-\bar{a}_{j} \lambda\right\}, \\
\omega_{2}^{\text {pes }}=\left\{n+1 \leq j \leq N \mid \underline{c}_{j}-\bar{a}_{j} \lambda\right\} .
\end{gathered}
$$

Moreover, $f_{*}^{o p}$ and $f_{*}^{\text {pes }}$ mean optimistic and pessimistic values of the objective function [4].

Thus, the following theorem 1 is proved:

Theorem1. The following inequalities are valid:

and

$$
f_{*}^{o p} \leq \min _{\lambda \geq 0} L^{o p}(\lambda)
$$

$$
f_{*}^{\text {pes }} \leq \min _{\lambda \geq 0} L^{\text {pes }}(\lambda)
$$

First of all, it should be noted that the functions $L^{o p}(\lambda)$ and $L^{\text {pes }}(\lambda)$ are continuous, since the variable $\lambda \geq 0$ varies continuously. On the other hand, these functions are piecewise linear, because they depend on the sets $\omega_{1}^{o p}, \omega_{2}^{o p}, \omega_{1}^{p e s}$ and $\omega_{2}^{p e s}$, which, by changing these sets, the direction of the lines change. Therefore, they are non-differentiable. Thus, the following Theorem 2 is proved.

Theorem 2. The functions $L^{o p}(\lambda)$ and $L^{\text {pes }}(\lambda)$ are continuous, piecewise linear, non-differentiable and convex.

Note that we skip over the proof of the convexity of these functions, since they take up a large place.

From this theorem it follows that the functions $L^{o p}(\lambda)$ and $L^{\text {pes }}(\lambda)$ have unique minima, respectively. As these functions are non-differentiable, then the gradient methods for minimizing are not applicable. Therefore, in this paper, we have developed an algorithm for minimizing functions $L^{o p}(\lambda)$ and $L^{\text {pes }}(\lambda)$ by coordinate-wise descent. To submit the algorithm for minimizing the function $L^{o p}(\lambda)$ we write this function in the following form:

$$
\begin{gathered}
L^{o p}(\lambda)=C\left(\omega_{1}^{o p}\right)+C\left(\omega_{2}^{o p}\right)+\left(b-A\left(\omega_{1}^{o p}\right)\right. \\
\left.-A\left(\omega_{2}^{o p}\right)\right) \cdot \lambda .
\end{gathered}
$$

Here

$$
C\left(\omega_{1}^{o p}\right)=\sum_{j \in \omega_{1}^{o p}} \bar{c}_{j}, \quad C\left(\omega_{2}^{o p}\right)=\sum_{j \in \omega_{2}^{o p}} \bar{c}_{j},
$$

$A\left(\omega_{1}^{o p}\right)=\sum_{j \in \omega_{1}^{o p}} \underline{a}_{j}, A\left(\omega_{2}^{o p}\right)=\sum_{j \in \omega_{2}^{o p}} \underline{a}_{j}, b \in[\underline{b}, \bar{b}]$ and is fixed.

At the beginning of the minimization process we accept $\lambda=0$. Then $\omega_{1}^{o p}=\{1,2, \ldots, n\}, \omega_{2}^{o p}=$ $\{n+1, n+2, \ldots, N\}$. In doing so, the inequality $(b-$ $\left.A\left(\omega_{1}^{o p}\right)-A\left(\omega_{2}^{o p}\right)\right) \leq 0$ is true. To find a positive value for $\lambda$, it is necessary to take into account the structure of the sets $\omega_{1}^{o p}$ and $\omega_{2}^{o p}$, i.e. for an optimistic problem $\quad \bar{c}_{j}-\underline{a}_{j} \cdot \lambda>0, \quad(j=\overline{1, n}), \quad \bar{c}_{j}-\underline{a}_{j} \cdot \lambda>$ $0,(j=\overline{n+1, N})$.

From here $\lambda<\bar{c}_{j} / \underline{a}_{j},(j=\overline{1, N})$. Then, it is clear, that it should be taken

$$
\lambda=\min _{j \in \omega_{1}^{o p} \cup \omega_{2}^{o p}}\left\{\frac{\bar{c}_{j}}{\underline{a}_{j}}\right\}=\frac{\bar{c}_{j_{*}}}{\underline{a}_{j_{*}}}
$$

Here, one should to take into account to which sets does $j_{*}$ belong. Therefore, we consider two cases:

If $j_{*} \in \omega_{1}^{o p}$, then we accept $\omega_{1}^{o p}:=\omega_{1}^{o p} \backslash\left\{j_{*}\right\}$. $C\left(\omega_{1}^{o p}\right)=C\left(\omega_{1}^{o p}\right)-\bar{c}_{j_{*}}, A\left(\omega_{1}^{o p}\right)=A\left(\omega_{1}^{o p}\right)+\underline{a}_{j_{*}}$.

If $j_{*} \in \omega_{2}^{o p}$, then we accept $\omega_{2}^{o p}:=\omega_{2}^{o p} \backslash\left\{j_{*}\right\}$. $C\left(\omega_{2}^{o p}\right)=C\left(\omega_{2}^{o p}\right)-\bar{c}_{j_{*}}, A\left(\omega_{2}^{o p}\right)=A\left(\omega_{2}^{o p}\right)+\underline{a}_{j_{*}}$ 
Therefore, the function $L^{o p}(\lambda)$ will take another form. Moreover, $\left(b-A\left(\omega_{1}^{o p}\right)-A\left(\omega_{2}^{o p}\right)\right)>0$ the minimization process ends. Otherwise, the function $L^{o p}(\lambda)$ can still be minimized. For this, from relation (14) we find the next new number $j_{*}$ and the minimization process continues in the above manner.

Note that after each selection of $j_{*}$ by formula (14), the coefficient $\left(b-A\left(\omega_{1}^{o p}\right)-A\left(\omega_{2}^{o p}\right)\right)$ of the variable $\lambda$ increases. Obviously, after a finite number of steps, this coefficient becomes non-negative. And this means that the above minimization process is completed after a finite number of steps.

Using this algorithm, we solve the following example:

$$
\begin{gathered}
{[1,1] x_{1}+[2,4] x_{2}+[1,6] x_{3}+[3,8] x_{4}+[1,3] x_{5}+[1,2] x_{6}+[3,4] x_{7}+[2,5] x_{8} \rightarrow \max } \\
{[6,9] x_{1}+[2,7] x_{2}+[6,10] x_{3}+[4,8] x_{4}+[9,11] x_{5}+[3,5] x_{6}+[5,6] x_{7}+[1,4] x_{8} \leq[10,20],} \\
0 \leq x_{j} \leq 1,(j=\overline{1,8}), \quad x_{j}=0 \vee 1,(j=\overline{1,5}) .
\end{gathered}
$$

At the beginning we accept $\lambda=0$. Then by formula (11) we obtain: $\omega_{1}^{o p}=\{1,2,3,4,5\}, \omega_{2}^{o p}=\{6,7,8\}$ and accept $b=20$. form:

Now, taking into account the above, the function $L^{o p}(\lambda)$ and $L^{p e s}(\lambda)$ by the formula (10), takes the following

$$
L^{o p}(\lambda)=22+11+(20-27-9) \cdot \lambda=33-16 \lambda
$$

The value of the function $L^{o p}(\lambda)$ in $\lambda=0$ of the function is equal to $L^{o p}(0)=33$ Then $C\left(\omega_{1}^{o p}\right)=22$, $C\left(\omega_{2}{ }^{o p}\right)=11, A\left(\omega_{1}^{o p}\right)=-27, A\left(\omega_{2}^{o p}\right)=-9, b=20$.

By the formula (14), we find the value for $\lambda$.

$$
\lambda=\min _{j \in \omega_{1} o p \cup \omega_{2} o p}\left\{\frac{1}{6} ; \frac{4}{2} ; \frac{6}{6} ; \frac{8}{4} ; \frac{3}{9} ; \frac{2}{3} ; \frac{4}{5} ; \frac{5}{1}\right\}=\frac{1}{6} .
$$

This value corresponds to the number $j_{*}=1$, which is included in the set of $\omega_{1}^{o p}$. Then

$\omega_{1}^{o p}=\{1,2,3,4,5\} \backslash\{1\}=\{*, 2,3,4,5\}, C\left(\omega_{1}^{o p}\right)=22-1=21, C\left(\omega_{2}^{o p}\right)=11, A\left(\omega_{1}^{o p}\right)=-27+6=-21$, $A\left(\omega_{2}^{o p}\right)=-9, b=20$. Therefore, the function $L^{o p}(\lambda)$ takes the following form:

$L^{o p}(\lambda)=21+11+(20-21-9) \cdot \lambda=32-10 \lambda$. The value of this function at $\lambda=1 / 6$ will be $L^{o p}\left(\frac{1}{6}\right)=32-10 \cdot \frac{1}{6}=30 \frac{2}{3}$. Since $\lambda=-10<0$, the minimization process continues. By the formula (14) we find the next value for $\lambda$.

$$
\lambda=\min _{j \in \omega_{1}^{o p} \cup \omega_{2} o p}\left\{* ; \frac{4}{2} ; \frac{6}{6} ; \frac{8}{4} ; \frac{3}{9} ; \frac{2}{3} ; \frac{4}{5} ; \frac{5}{1}\right\}=\frac{1}{3}
$$

This corresponds to the number $j_{*}=5$, which is from $\omega_{1}^{o p}$ i.e. $j_{*} \in \omega_{1}^{o p}$. Then $\omega_{1}{ }^{o p}=\{* ; 2 ; 3 ; 4 ; 5\} \backslash\{5\}=\{* ; 2 ; 3 ; 4 ; *\}$,

$C\left(\omega_{1}^{o p}\right)=21-3=18, C\left(\omega_{2}^{o p}\right)=11, A\left(\omega_{1}^{o p}\right)=-21+9=-12, A\left(\omega_{2}^{o p}\right)=-9, b=20$.

Thus, the function $L^{o p}(\lambda)$ takes the following form:

$$
L^{o p}(\lambda)=18+11+(20-12-9) \cdot \lambda=29-1 \cdot \lambda . \text { In doing so, } L^{o p}\left(\frac{1}{3}\right)=29-1 \cdot \frac{1}{3}=28 \frac{2}{3} .
$$

Since the coefficient $\lambda$ is still negative, the minimization process is still ongoing.

$$
\lambda=\min _{j \in \omega_{1}^{o p} \cup \omega_{2} o p}\left\{* ; \frac{4}{2} ; \frac{6}{6} ; \frac{8}{4} ; * ; \frac{2}{3} ; \frac{4}{5} ; \frac{5}{1}\right\}=\frac{2}{3} .
$$

And this corresponds to the number $j_{*}=6$, which belong to $\omega_{2}^{o p}$, i.e. $j \in \omega_{2}^{o p}$. Then $\omega_{2}^{o p}=\{6,7,8\}\{6\}$, $C\left(\omega_{1}^{o p}\right)=21-3=18, C\left(\omega_{2}^{o p}\right)=11-2=9, A\left(\omega_{1}^{o p}\right)=-21+9=-12$,

$A\left(\omega_{2}^{o p}\right)=-9+3=-6, b=20$.

Consequently, $L^{o p}(\lambda)=18+9+(20-12-6) \cdot \lambda=27+2 \cdot \lambda$.

In this $L^{o p}\left(\frac{2}{3}\right)=27+2 \cdot \frac{2}{3}=28 \frac{1}{3}$. Since the coefficient before $\lambda$ has become positive, the minimization process is completed. $\min _{j \in \omega_{1}^{o p} \cup \omega_{2} o p} L^{o p}(\lambda)=28 \frac{1}{3}$. This means that for an optimistic problem $f_{*} \leq 28 \frac{1}{3}$, i.e. the upper bound will be $28 \frac{1}{3}$.
Let us prove the following theorem 3 .

Theorem 3. The minimum values of $L^{o p}(\lambda)$ and $L^{\text {pes }}(\lambda)$ coincide with the maximum values of the objective functions of the optimistic and pessimistic conti-nuous problems (1) - (3), respectively.

Proof. Let the following optimistic problem be considered:

$$
\sum_{j=1}^{N} \bar{c}_{j} x_{j} \rightarrow \max
$$




$$
\begin{gathered}
\sum_{j=1}^{N} \underline{\boldsymbol{a}}_{j} \boldsymbol{x}_{j} \leq \boldsymbol{b}, \\
0 \leq x_{j} \leq 1,(j=\overline{1, N}), \\
x_{j}=1 \vee 0,(j=\overline{1, n} ; n \leq N) .
\end{gathered}
$$

To determine the upper bound of the maximum First of all, we note that, without loss of generality, value of the function (15) in the problem (15) - (18), we can assume that the coefficients of problems (15) generally continuous relaxation of problem (15) - (18) (16) are arranged in the following order: is solved.

$$
\frac{\bar{c}_{1}}{\underline{a}_{1}} \geq \frac{\bar{c}_{2}}{\underline{a}_{2}} \geq \cdots \geq \frac{\bar{c}_{k}}{\underline{a}_{k}} \geq \cdots \geq \frac{\bar{c}_{N}}{\underline{a}_{N}} .
$$

Then the optimal solution to problem (15) - (17) is determined analytically by the following formula for each $j,(j=1,2, \ldots, N)$.

$$
\bar{x}_{j}=\left\{\begin{array}{l}
1, \text { if } \underline{a}_{j} \leq b-\sum_{i=1}^{j-1} \underline{a}_{i} \bar{x}_{i}, \\
\left(b-\sum_{i=1}^{j-1} \underline{a}_{i} \bar{x}_{i}\right) / \underline{a}_{j}, \text { if } \underline{a}_{j}>b-\sum_{i=1}^{j-1} \underline{a}_{i} \bar{x}_{i},(k:=j), \\
0, j=\overline{k+1, N .}
\end{array}\right.
$$

Moreover, the upper bound of the maximum value of the mixed- Boolean problem (15) - (18) will be

$$
\bar{f}_{o p}=\sum_{j=1}^{N} \bar{c}_{j} \bar{x}_{j}
$$

We write formula (19) in a slightly different way:

Firstly, we accept

$$
b:=b-\sum_{j=1}^{N} \underline{a}_{j},
$$

where $b$ will be negative. We construct the solution $\bar{X}=\left(\bar{x}_{1}, \bar{x}_{2}, \ldots, \bar{x}_{N}\right)$ for each $j,(j=N, N-1, N-2, \ldots, 1)$ as follows:

$$
\bar{x}_{j}=\left\{\begin{array}{l}
0, \text { if } b+\sum_{i=j}^{N} \underline{a}_{i}<0 \\
\left(b+\sum_{i=j}^{N} \underline{a}_{i}\right) / \underline{a}_{j}, \text { if }\left(b+\sum_{i=j}^{N} \underline{a}_{i}\right) \geq 0,(k:=j), \\
1, j=k-1, k-2, \ldots, 1 .
\end{array}\right.
$$

Obviously, the solutions $\bar{X}$ obtained by formulas (19) - (20) coincide. On the other hand, according to formula (20), unknowns take zero values corresponding to the lowest value $\bar{c}_{j} / \underline{a}_{j}$ consistently

$$
\min L^{o p}(\lambda)=\bar{f}_{o p}=\sum_{j=1}^{N} \bar{c}_{j} \cdot \bar{x}_{j}
$$

In a similar way, one can prove that $\min L^{\text {pes }}(\lambda)=\bar{f}_{\text {pes }}=\sum_{j=1}^{N} \underline{c}_{j} \cdot \underline{x}_{j}$.

Thus, the theorem is proved.

Corollary. This theorem directly shows that to find the upper bound of the optimistic and pessimistic problem (1)-(4), one should not use the linear programming apparatus, since the results of minimizing the functions $L^{o p}(\lambda)$ and $L^{\text {pes }}(\lambda)$ give the values of the upper bound that coincide with the values obtained by using the linear programming apparatus.

4. Results of computational experiments.

Since the minimum upper bounds of the optimistic and pessimistic problems found by the algorithms developed in this work coincide with the maximum
$(j=N, N-1, N-2, \ldots, 1)$. And this totally corresponds to the above minimization algorithm of the function $L^{o p}(\lambda)$. Thus, it is proved that 
-It was proved that the minimum value of the constructed majorizing function coincide with the maximum value of the objective function of the corresponding continuous problem (1) - (3).

\section{Acknowledgement}

In conclusion, I express my sincere gratitude to my research supervisor prof. K.Sh. Mammadov for participating in the discussion and valuable advice.

\section{References}

1.Libura M., Integer programming problems with inexact objective function // Control And Cybernetics. -1980. - Vol. 9, № 4. -P.189-202.

2.Девятерикова М.В., Колоколов А.А., Колосов А.П., Алгоритмы перебора L-классов для булевой задачи о рюкзаке с интервальными данными Материалы III Всероссий-ской конференции "Проблемы оптимизации и экономическое приложение" // Омск: Изд-во Ом ГТУ. -2006.-С. 87.

3.Emelichev V.A., Podkopaev D.P., Quantitative stability analysis for vector problems of $0-1$ programming // Discrete Optimitation.- 2010.- № 7.P.48-63.

4.Мамедов К.Ш., Мамедли Н.О., Методы построения субоптимистического и субпессимистического решений частично-Булевой задачи о ранце с интервальными данными // Изв. НАН Азербайджана.- 2016.- № 6.- с.6-13.

5.Мамедов К.Ш., Мамедова А.Г., Понятия субоптимистического и субпессимистичес-кого решений и построение их в интервальной задаче Булевого программирования // Радиоэлектроника, Информатика, Управление.- 2016.-№ 3.- с. 99-107.
6.Mamedov K.Sh., Mammadli N.O., Two methods for construction of suboptimistic and subpessimistic solutions of the interval problem of mixed Boolean programming // Radio Electronics, Computer Science, Control.-2018.- №3(46). DOI 10/15588/1607-3274-2018-3-7.

7.Bukhtoyarov S.E., Emelichev V.A., Stability aspects of Multicriteria integer linear programming problem // Journal of Applied and Industrial mathematics.- 2019.- V(13). -№1.- pp.1-10.

8.Бухтояров С.Е., Емеличев В.А., Инвестиционная булева задача с критериями рисков Севиджа в условиях неопределенности // Дискретная матем-ка.- 2019.- Т 31.- №2.- с.20-33.

9.Emelichev V.A., Kuzmin K.J., On the T stability radious of a multicriteria linear Boolean problem with Helder norm in parameter spaces // Tavricheskiy Vestnik Math.inform.- 2016. 30 1.pp.49-64.

10. Hladik M. On strong optimality of interval linear programming // Optim.Lett . - 2017. —11(7). P.1459-1468

https://doi: 10.1007/s11590-016-1088-3

11. Li W., Liu X., Li H., Generalized solutions to interval linear programs and related necessary and sufficient optimality conditions // Optim. Methods Softw . 2015.-30(3) . - P.516-530.

12. Mostafaee A., Hladik M., Cerny M. Inverse linear programming with interval coefficients // J.Comput. Appl.Math. —2016. —292:591-608.

13. К.Ш.Мамедов, Н.О.Мамедли, Методы построения приближённого решения интервальной задачи частично-целочисленного программирования // ЕСУ, 2019, № 4(61), с.29-36. DOI:10.31618/ESU.2413-9335.2019.1.61.2.

\section{ЭНЕРГИЯ СВЯЗИ ФЕРМИОНА С КАПЛЕЙ БОЗЕ-КОНДЕНСАТА}

DOI: $10.31618 /$ ESU.2413-9335.2019.2.66.306

Мастропас Зинаида Петровна

канд. физ.-мат. наук,

доцент кафедры общей физики,

Южный федеральный университет, г. Ростов-на-Дону

\section{ON ENERGY OF A FERMION COUPLED WITH A DROP OF BOSE CONDENSATE}

Mastropas Z.P. candidate of physical and mathematical sciences, associate Professor, Physics Department Chair, Southern Federal University, Rostov-on-Don

\section{АННОТАЦИЯ}

Методами квантовой теории поля исследована система из одного реального фермиона, сильно взаимодействующего с векторным бозе-полем. Установлено, что основным состоянием такой системы в случае адиабатического приближения является состояние двух связанных волновых пакетов. Гармоники бозе-поля находятся в квантово-когерентных состояниях, а само бозе-поле содержит бозе-конденсат. Доказано, что бозе-конденсат, сопровождающий перемещение устойчивого адрона, является когерентной составляющей собственного поля адрона, а потенциал этого поля естественно оказывается потенциалом Юкавы.

\section{ABSTRACT}

This research carried out using quantum field theory methods investigates the system of one real fermion strongly interacting with vector bosonic field. It is shown that, in case of adiabatic approximation, the ground state of such system is a state of two coupled wave packets. The harmonics of Bose field turn out to be in quantumcoherent states, while bosonic field itself contains a Bose condensate. This study proves that Bose condensate 